\title{
Skin autofluorescence as a novel predictor of acute kidney injury after liver resection
}

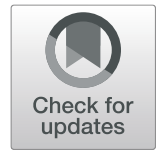

\author{
Maciej Krasnodębski ${ }^{1 *}$ D, Karolina Grąt ${ }^{2}$, Marcin Morawski ${ }^{1}$, Jan Borkowski ${ }^{1}$, Piotr Krawczyk' ${ }^{1}$, Andriy Zhylko \\ Michał Skalski ${ }^{1}$, Piotr Kalinowski ${ }^{1}$, Krzysztof Zieniewicz $^{1}$ and Michał Grąt ${ }^{1}$
}

\begin{abstract}
Background: Skin autofluorescence (SAF) reflects accumulation of advanced glycation end-products (AGEs). The aim of this study was to evaluate predictive usefulness of SAF measurement in prediction of acute kidney injury (AKI) after liver resection.

Methods: This prospective observational study included 130 patients undergoing liver resection. The primary outcome measure was AKI. SAF was measured preoperatively and expressed in arbitrary units (AU).

Results: AKI was observed in 32 of 130 patients (24.6\%). SAF independently predicted AKI ( $p=0.047)$, along with extent of resection $(p=0.019)$ and operative time $(p=0.046)$. Optimal cut-off for SAF in prediction of AKI was 2.7 $\mathrm{AU}$ (area under the curve $[\mathrm{AUC}]$ 0.611), with AKI rates of $38.7 \%$ and $20.2 \%$ in patients with high and low SAF, respectively ( $p=0.037$ ). Score based on 3 independent predictors (SAF, extent of resection, and operative time) well stratified the risk of AKI (AUC 0.756), with positive and negative predictive values of $59.3 \%$ and $84.0 \%$, respectively. In particular, SAF predicted AKI in patients undergoing major and prolonged resections $(p=0.010$, AUC 0.733) with positive and negative predictive values of $81.8 \%$, and $62.5 \%$, respectively.
\end{abstract}

Conclusions: AGEs accumulation negatively affects renal function in patients undergoing liver resection. SAF measurement may be used to predict AKI after liver resection, particularly in high-risk patients.

Keywords: Skin autofluorescence, Acute kidney injury, Liver resection

\section{Background}

Skin autofluorescence (SAF) is an indirect measure of systemic accumulation of advanced glycation end products (AGEs). Proteins, lipids, and nucleic acids form AGEs throughout the lifetime in the presence of hyperglycemia through non-enzymatic Maillard reaction [1]. Alternatively, AGEs may be created as a consequence of reactions with particles formed under oxidative stress or are delivered to the human body with food or tobacco smoke. Therefore, age-related accumulation of AGEs is often considered as a marker of "cumulative metabolic stress" or "metabolic memory" $[1,2]$.

\footnotetext{
* Correspondence: mwkrasn@gmail.com

'Department of General, Transplant and Liver Surgery, Medical University of Warsaw, Warsaw, Poland

Full list of author information is available at the end of the article
}

Wide spectrum of AGEs includes both fluorescent particles, such as pentosidine and pentodilysine, and non-fluorescent particles, such as $N^{\varepsilon}$-carboxymethyl-lysine and $N^{\varepsilon}$-carboxyethyl-lysine [3, 4]. Although SAF measurement is based on the amount of fluorescent AGEs, it is also correlated to non-fluorescent AGE content [5]. Increased accumulation of AGEs was found to be associated with atherosclerosis and vascular dysfunction, cardiovascular morbidity and mortality, peripheral artery disease, diabetes and related complications, and in particular, chronic kidney disease [5-18]. Pathogenic effects of AGEs comprise both cross-linking of other proteins with subsequent damage of extracellular matrix and activation of receptor-dependent downstream inflammatory cascades involving nuclear factor kappa-B $[3,4,16]$. In kidneys, AGE-related organ injury is largely driven by accumulation of methylgloxal, a process 
referred to as dicarbonyl stress [19]. Accumulating AGEs induce podocyte injury, oxidative damage, and angiotensinogen overexpression [20-22]. Those pathogenetic mechanisms may also promote acute kidney injury (AKI) in susceptible patients, yet whether AGE accumulation is associated with increased risk of developing AKI in the postoperative period after major abdominal operations remains unknown.

AKI occurs commonly in patients undergoing liver resection with an estimated incidence of $8.2-53.8 \%$, as opposed to a $6-13.4 \%$ rate in patients after major abdominal surgery in general [23-29]. It is associated with increased morbidity and mortality rates [23, 24]. Prolonged operative time, extent of liver resection, preoperative kidney function, and patient age were previously commonly identified as important risk factors [23, $24,28]$. The standard definition of AKI is based on the Kidney Disease Improving Global Outcomes (KDIGO) criteria including serum creatinine increase by $0.3 \mathrm{mg} /$ $\mathrm{dL}$ over $48 \mathrm{~h}$ or $50 \%$ over 7 days or urine output $<0.5$ $\mathrm{mL} / \mathrm{kg} / \mathrm{h}$ for $6 \mathrm{~h}$ [30]. However, lack of clinical relevance of isolated oliguria without creatinine increase was recently confirmed in liver resection studies [25, 27]. Creatinine-only criteria for defining AKI were also approved outside the clinical care setting in a 2020 report from Improving Global Outcomes (KDIGO) Consensus Conference [31].

The primary hypothesis for this study was that increased accumulation of AGEs is a risk factor for developing AKI in patients undergoing liver resection. The aim was to evaluate whether SAF measurement may be used for prediction of AKI after liver resection.

\section{Methods}

This was a prospective observational study performed in the Department of General, Transplant and Liver Surgery of the Medical University of Warsaw between December 2018 and November 2019. Inclusion criteria comprised open liver resection for suspected malignancy, age between 18 and 70 years, and provision of informed consent. Patients with skin phototypes IV-VI in Fitzpatrick's classification, and those with body mass index $(\mathrm{BMI})>35 \mathrm{~kg} / \mathrm{m}^{2}$ were excluded. The study protocol was approved by the institutional review board of the Medical University of Warsaw. All participants provided informed consent before inclusion in the study.

The primary outcome measure was AKI within 7 postoperative days. It was defined according to KDIGO criteria as either increase in serum creatinine concentration by at least $0.3 \mathrm{mg} / \mathrm{dL}$ over $48 \mathrm{~h}$ or by at least $50 \%$ over 7 days. Stage I, II, and III AKI were further defined as a serum creatinine concentration increase by $50-99 \%, 100-199 \%$, and over 200\%, respectively. Stage II and III AKI was considered severe
[30]. Urine output was not considered for the purpose of diagnosing AKI.

SAF was the primary factor of interest. It was measured using AGE Reader (Diagnoptics Technologies B.V., Groningen, The Netherlands) based on a system of photodiodes. Following illumination of approximately 4 $\mathrm{cm}^{2}$ of skin with light wavelength between 300 and 420 $\mathrm{nm}$ with peak intensity at $370 \mathrm{~nm}$, the light emitted and reflected by the skin was assessed. SAF value was expressed in arbitrary units (AU), expressing the ratio of average intensity of emitted light with wavelength of $420-600 \mathrm{~nm}$ to average intensity of reflected light with the wavelength of $300-420 \mathrm{~nm}$, multiplied by 100 . Measurements were done in the immediate preoperative period on the anterior side of the forearm, approximately $10 \mathrm{~cm}$ below the elbow fold. Average value from 3 separate assessments was included in the analyses.

Liver resections were performed through bilateral subcostal incisions. Parenchymal transection was done with either ultrasonic or waterjet device. Pringle maneuver was applied selectively. Major resections were defined as removal of more than 2 Couinaud segments. Postoperatively, patients were transferred to surgical intensive care unit for at least $24 \mathrm{~h}$. Serum creatinine concentration was routinely assessed preoperatively and postoperatively at the day of operation, day 1 , day 3 or 4 , and in subsequent days, when clinically indicated. Severe morbidity was defined as development of complication of grades III-V in the Clavien-Dindo classification [32].

Quantitative and qualitative variables were presented as medians with interquartile ranges and as numbers with frequencies, respectively. Chi-square test and Mann-Whitney $U$ test were used for intergroup comparisons of qualitative and quantitative variables. Logistic regression was used for univariable and multivariable analyses of risk factors for AKI. Preoperative creatinine concentration and factors significantly associated with AKI were included in the multivariable model. Receiver operating characteristics (ROC) analyses were performed to choose optimal cut-offs of quantitative variables in prediction of AKI, basing on the highest Youden index. Odds ratios (ORs) and areas under the curve (AUCs) were presented with $95 \%$ confidence intervals. The level of significance was set at 0.05 . STATISTICA version 13 (TIBCO Software Inc., Palo Alto, USA) software was used for computing statistical analyses.

\section{Results}

A total of 130 patients were included in the study. Baseline characteristics of the study cohort are presented in Table 1. Any-stage AKI was diagnosed in 32 patients (24.6\%), including 9 with severe AKI (6.9\%). In particular, stage I, stage II, and stage III AKI occurred in 23,8 , and 1 patient, respectively. None of them required renal 
Table 1 Baseline characteristics of 130 patients included in the study cohort

\begin{tabular}{ll}
\hline & Median (IQR) or $\mathbf{n}$ (\%) \\
\hline Patient sex & $67(51.5 \%)$ \\
male & $63(48.5 \%)$ \\
female & $60(51-65)$ \\
Patient age (years) & $2.3(1.9-2.6)$ \\
Skin autofluorescence (AU) & $26.7(23.9-29.7)$ \\
Body mass index (kg/m $\left.{ }^{2}\right)$ & $16(12.3 \%)$ \\
Diabetes & $44(33.8 \%)$ \\
Arterial hypertension & \\
Preoperative laboratory tests & $6.1(5.3-7.7)$ \\
white blood count (10 $\left.3 / \mathrm{mm}^{3}\right)$ & $13.4(12.7-14.1)$ \\
hemoglobin (g/dL) & $223(190-263)$ \\
platelets (10 $\left.{ }^{3} / \mathrm{mm}^{3}\right)$ & $0.8(0.7-1.0)$ \\
creatinine (mg/dL) & $0.5(0.4-0.7)$ \\
bilirubin (mg/dL) & $1.0(1.0-1.1)$ \\
INR &
\end{tabular}

IQR interquartile range, $\mathrm{AU}$ arbitrary unit, INR international normalized ratio

replacement therapy in the 7-day postoperative period. Severe morbidity rate was $8.5 \%$ (defined as development of complication of grades III-V in the Clavien-Dindo classification) [32]. The length of stay did not differ between patients without and with AKI (median 7 vs. 7.5 days, $p=0.063$ ), but was significantly longer for severe AKI (median 7 vs. 11 days, $p=0.008$ ). One patient died in the postoperative period in the course of massive pneumonia.

SAF was a significant predictor of AKI on univariable analysis $(p=0.039$; Table 2$)$. Other risk factors comprised operative time $(p=0.001)$, male sex $(p=0.010)$, and major liver resection $(p<0.001)$. SAF was independently associated with the development of AKI $(p=$ $0.047)$, in addition to the extent of liver resection ( $p=$ $0.019)$ and operative time $(p=0.046)$ in a multivariable model including those 3 variables, patient sex, and
Table 2 Analyses of risk factors for the occurrence of acute kidney injury after liver resection

\begin{tabular}{llllll}
\hline Factors & Univariable & & & Multivariable & \\
\cline { 2 - 3 } & OR $(\mathbf{9 5} \% \mathbf{C l})$ & $\mathbf{p}$ & & OR $(\mathbf{9 5} \% \mathrm{Cl})$ & $\mathbf{p}$ \\
\hline Male sex & $1.75(1.14-2.67)$ & .010 & & $1.35(0.81-2.27)$ & .252 \\
Patient age & $1.03(0.99-1.08)$ & .110 & & \\
Skin autofluorescence & $1.98(1.03-3.80)$ & .039 & & $2.16(1.01-4.62)$ & .047 \\
Body mass index & $1.02(0.93-1.12)$ & .729 & & \\
Diabetes & $1.66(0.97-2.86)$ & .065 & & \\
Arterial hypertension & $1.22(0.81-1.84)$ & .352 & & \\
Preoperative creatinine & $2.72(0.58-12.87)$ & .206 & $0.61(0.08-4.31)$ & .616 \\
Major liver resection & $2.49(1.58-3.91)$ & $<.001$ & & $1.83(1.10-3.05)$ & .019 \\
Operative time & $1.67(1.23-2.26)$ & .001 & & $1.43(1.01-2.04)$ & .046 \\
\hline
\end{tabular}

OR - odds ratio; $95 \% \mathrm{Cl}$ - 95\% confidence interval. Odds ratios were calculated per: 1 year increase for patient age; 1 arbitrary unit increase for skin autofluorescence; $1 \mathrm{~kg} / \mathrm{m}^{2}$ increase for body mass index; $1 \mathrm{mg} / \mathrm{dL}$ increase for preoperative creatinine; 1 hour increase for operative time

preoperative creatinine concentration. The optimal cutoffs for SAF and operative time in prediction of AKI were $2.7 \mathrm{AU}$ and $3.5 \mathrm{~h}$, respectively, with the corresponding AUCs of 0.611 (95\% CI 0.499-0.723; Fig. 1A) and 0.718 (95\% CI 0.623-0.813; Fig. 1B). Sensitivity, specificity, PPV, and NPV were $37.5 \%, 80.6 \%, 38.7 \%$, and $79.8 \%$, respectively, for the established SAF cut-off, and $81.3 \%, 56.8 \%, 38.8 \%$, and $90.0 \%$, respectively, for the established operative time cut-off. The rate of AKI in patients with SAF $\geq 2.7 \mathrm{AU}$ was $38.7 \%$ (12 of 31 ) as compared to $20.2 \%$ (20 of 99) in patients with $\mathrm{SAF}<2.7 \mathrm{AU}$ $(p=0.037)$.

A risk score for AKI basing on SAF, operative time, and extent of liver resection $([0.771 \times \mathrm{SAF}]+[0.359 \times$ operative time in hours] +0.607 if major resection) was associated with AUC of 0.756 (95\% CI 0.658-0.854). Sensitivity, specificity, PPV, and NPV rates were $50.0 \%$, $88.4 \%, 59.3 \%$, and $84.0 \%$, respectively, for a risk score cut-off of 4.188 (Fig. 2). AKI occurred in 59.3\% (16 of 27) of patients with risk score value $\geq 4.188$ as compared to $16.0 \%$ (16 of 100$)$ of patients with lower values $(p<$ $0.001)$.

Regardless of SAF, AKI occurred in 6.4\% (3 of 47) of patients after minor resections lasting $<3.5 \mathrm{~h}$, in $20.8 \%$ (5 of 24) of patients undergoing minor resections lasting $\geq 3.5 \mathrm{~h}$, in $23.1 \%$ ( 3 of 13 ) of patients after major resections lasting $<3.5 \mathrm{~h}$, and in $48.8 \%$ (21 of 43 ) of patients undergoing major resections lasting $\geq 3.5 \mathrm{~h}(p<0.001)$. SAF was a significant risk factor for developing AKI in the high-risk group of patients undergoing major resections lasting $\geq 3.5 \mathrm{~h}(p=0.010$; Table 3$)$. The optimal cut-off for SAF in prediction of AKI in this high-risk subgroup was also $2.7 \mathrm{AU}$ with AUC of 0.733 (95\% CI 0.584-0.882) and sensitivity, specificity, PPV, and NPV rates of $42.9 \%, 90.9 \%, 81.8 \%$, and $62.5 \%$, respectively 

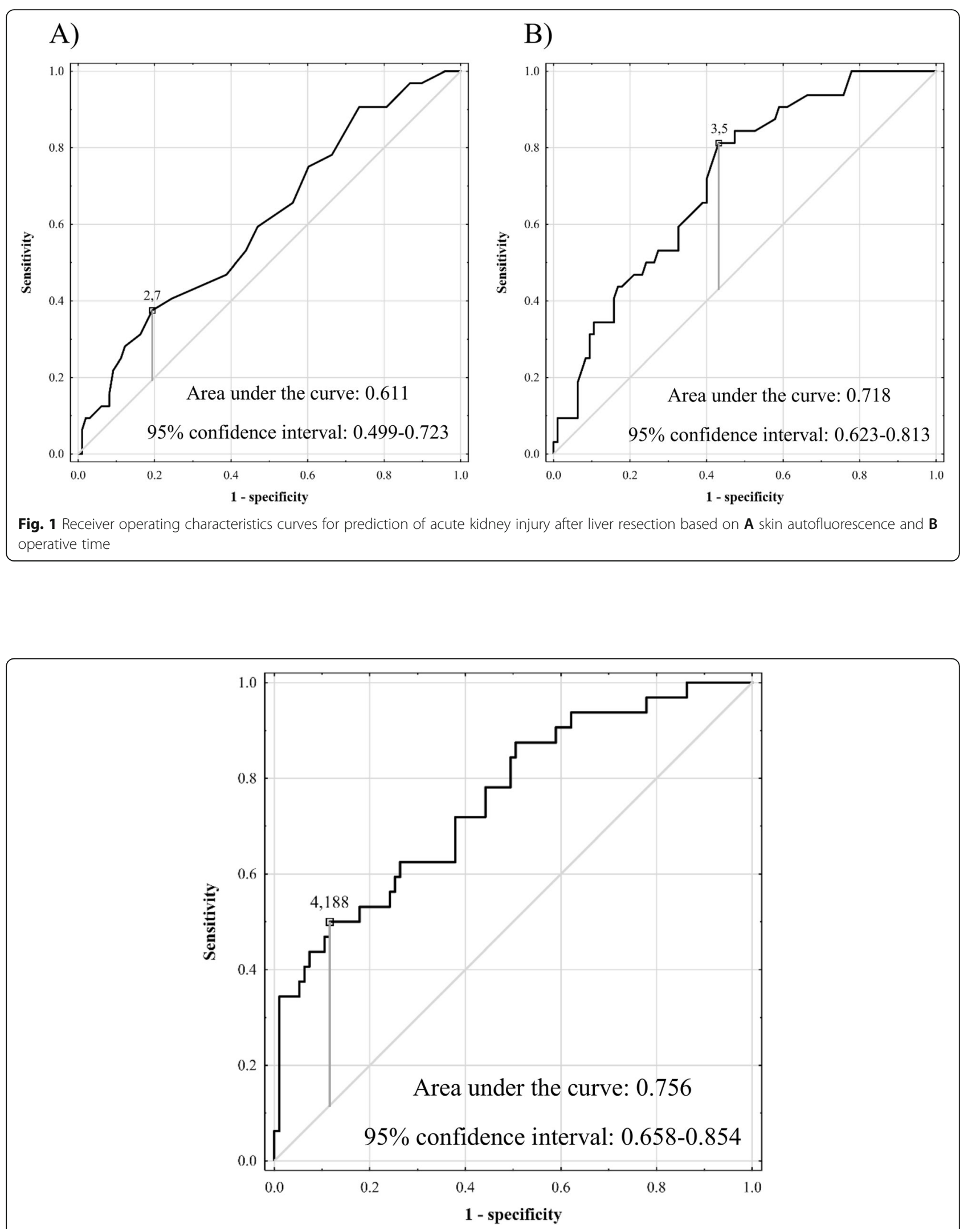

Fig. 2 Receiver operating characteristics curve for prediction of acute kidney injury after liver resection based on a risk score utilizing skin autofluorescence, extent of resection, and operative time 
Table 3 Subgroup analyses of the associations between skin autofluorescence and occurrence of acute kidney injury after liver resection

\begin{tabular}{llll}
\hline Subgroup & Factor & OR $(\mathbf{9 5 \%}$ Cl) & p \\
\hline Major resections lasting $\geq 3.5$ hours & SAF & $6.69(1.57-28.58)$ & .010 \\
Major resections lasting $<3.5$ hours or minor resections lasting $\geq 3.5$ hours & SAF & $0.48(0.11-2.09)$ & .329 \\
Minor resections lasting $<3.5$ hours & SAF & $-^{a}$ & $-^{a}$ \\
\hline
\end{tabular}

a - not calculated due to only 3 events in the subgroup. OR - odds ratio; $95 \% \mathrm{Cl}-95 \%$ confidence interval; SAF - skin autofluorescence. Odds ratios were calculated per 1 arbitrary unit increase

(Fig. 3). In subgroup analysis of patients undergoing major resections lasting $\geq 3.5 \mathrm{~h}$, the rate of AKI was 81.8\% (9 of 11) in case of SAF $\geq 2.7 \mathrm{AU}$ as compared to $37.5 \%$ (12 of 32) in case of lower SAF values $(p=0.011)$.

In contrast to any-stage AKI, the association between SAF and development of severe AKI was not significant (OR 2.19 per 1 AU increase; 95\% CI 0.80-5.99; $p=$ $0.126)$.

\section{Discussion}

Although the pathogenic role of systemic accumulation of AGEs in development and progression of chronic kidney disease is being intensively studied, there was no available data regarding development of AKI in postoperative setting $[1,3,18,19]$. Only a single previous report pointed towards higher SAF values in patients admitted for AKI in general [33]. This study provides first data on the negative effects of AGEs accumulation on development of AKI in patients undergoing liver resection. The present results indicate that SAF, as an indirect measure of AGEs skin content, may be applied for preoperative prediction of AKI.

Considering all patients undergoing liver resection, the association between SAF and development of AKI was significant, yet the predictive performance of SAF was limited as reflected by low AUC, low sensitivity, and moderate specificity. Nevertheless, the use of SAF cutoff of 2.7 AU points towards identification of patients at nearly doubled risk of developing AKI in the postoperative period. Further, PPV of nearly $40 \%$ observed for the established SAF cut-off is remarkably better than the $25 \%$ PPV related to intraoperative oliguria in major abdominal surgery [34]. Consistent with other reports, extent of liver resection and duration of surgical procedure

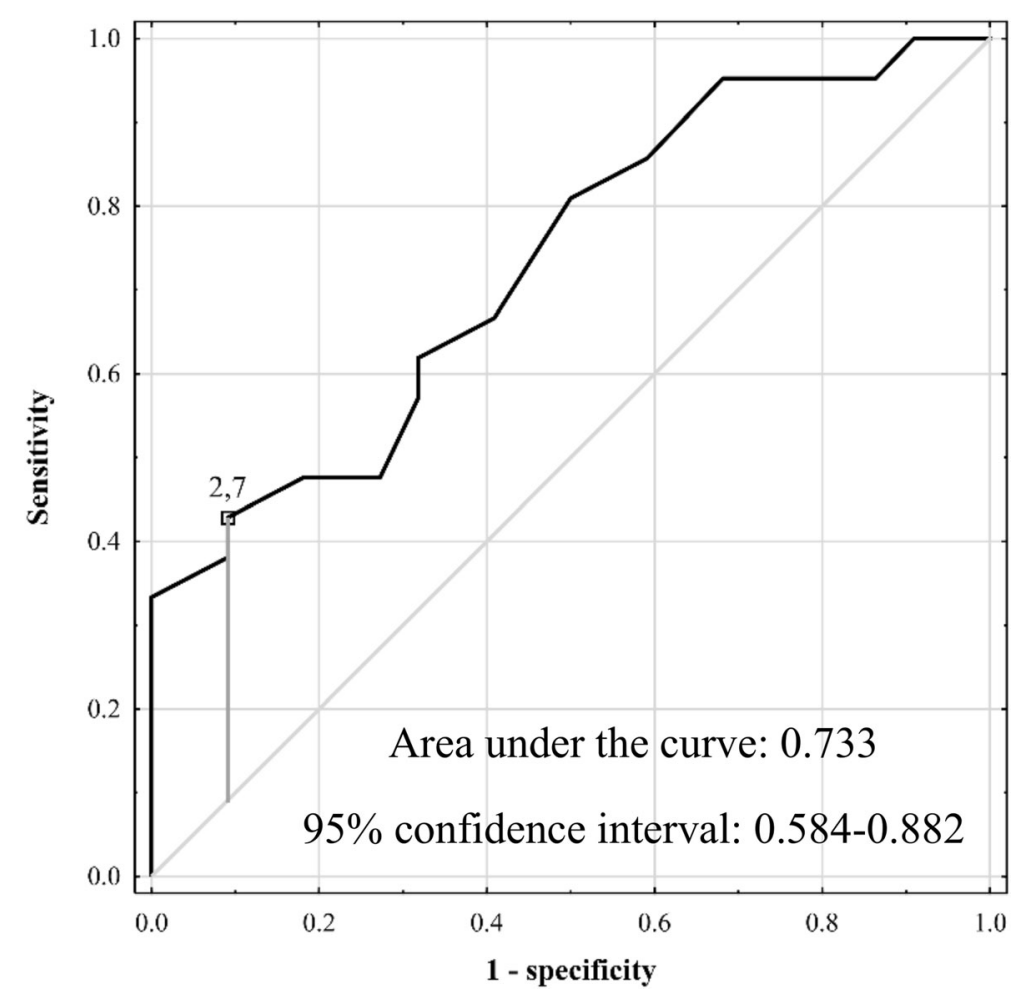

Fig. 3 Receiver operating characteristics curves for prediction of acute kidney injury after liver resection based on skin autofluorescence in a subgroup of patients undergoing major resections lasting $\geq 3.5 \mathrm{~h}$ 
were the two main determinants of AKI occurrence in patients undergoing liver resection [23-25, 28, 35]. As preoperative serum creatinine concentration was previously commonly identified as important predictor of AKI, it was included in the multivariable model despite a lack of significance on univariable analysis $[28,36]$. Importantly, the association between SAF and occurrence of AKI remained significant following adjustment for the confounding effects of extent of liver resection and its duration, preoperative kidney function, and patient sex.

While the prediction of AKI based only on SAF was suboptimal and useful for general stratification of patients into low- and high-risk group, a risk score based on SAF, extent of resection and operative time seems to enable more accurate prediction. Assuming precise preoperative planning and estimation of operative time, application of the simple 3-factor score may lead to preoperative prediction of half of all AKI cases with nearly 6 of 10 patients with positive prediction developing AKI. Notably, despite its simplicity due to inclusion of only 3 variables, an AUC of 0.756 seems favorable compared to the corresponding values reported for far more complex models. In a study by Slankamenac et al., a model based on 7 preoperative variables, namely cardiovascular disease, chronic renal failure, diabetes, serum alanine transaminase activity and bilirubin concentration, age, and sex was associated with an AUC of 0.80 [37]. Further studies by the same group revealed similar AUC of 0.81 for combination of that preoperative score with intraoperative parameters [38]. Regarding prediction of AKI after major gastrointestinal surgery in general, a 6-variable model provided a c-statistic of 0.66 [36]. Notably, AUCs for algorithms based on machine learning were in the range of $0.628-0.772$ [39]. On the contrary, an AUC of nearly 0.90 was found for urine neutrophil gelatinase-associated lipocalin (NGAL) concentration assessed $12 \mathrm{~h}$ postoperatively, yet these results seem to be related to early detection of AKI rather than prediction of its development [40]. Considering that urine NGAL measurement is not performed routinely despite its high accuracy, the results of the present study point towards measuring NGAL for early detection of AKI in patients with high risk score values.

Potential advantages in clinical application of SAF measurement in prediction of AKI in patients after liver resection are clearly visible in patients at otherwise the highest risk of its development. While prolonged excessive liver resections are obviously associated with the highest risk of developing AKI, SAF efficiently stratifies patients into high and almost ultimate risk of recurrence. Accordingly, the risk of AKI was below 10\% in patients after minor resections not exceeding $3.5 \mathrm{~h}$, approximately $20 \%$ in those after minor resections exceeding 3.5 $\mathrm{h}$ and after major resections not exceeding $3.5 \mathrm{~h}$, and nearly $50 \%$ in those undergoing major resections lasting over $3.5 \mathrm{~h}$. Importantly, the SAF cut-off value of $2.7 \mathrm{AU}$ well-stratified the patients into those with approximately $80 \%$ and $40 \%$ risk of AKI. From a clinical point of view, SAF measurement at the level of or exceeding 2.7 AU may be considered as indicating AKI in the postoperative period after major long-lasting liver resections.

The general incidence of AKI reported in the present study is relatively high, considering previous relevant reports [23-25, 28, 41, 42]. However, in contrast to previous studies, the present analysis was based on a prospective observational study, potentially increasing its sensitivity regarding AKI detection in the absence of clinical symptoms. This is supported by the similarity in cumulative incidence of stage II and stage III AKI, referred to as severe, between the present and previous reports [23, 24]. Notably, while no significant association was found between SAF and development of severe AKI, the incidence was more than 3-fold higher in patients with SAF equal to or exceeding 2.3 AU. Whether a lack of statistical significance is due to a lack of true association or due to lack of power remains an open question, yet the present study is obviously underpowered to detect differences in severe AKI rates dependent upon SAF values.

The present study is subject to several limitations. First, accumulation of AGEs was measured indirectly by assessment of SAF and does not provide any data regarding particular AGEs relevant in the pathogenesis of postoperative AKI. Second, estimation of AGE content basing on SAF measurement may be confounded by the presence of other skin fluorophores, such as nicotinamide adenine dinucleotide [43]. Nevertheless, SAF was previously validated as a relatively accurate measure of systemic accumulation of AGEs and SAF variance is primarily dependent upon AGE content [5, 43]. However, the potential casual/random relationship of SAF and AKI in the postoperative period cannot be underestimated as well. The AKI can occur due to multifactorial confounders that were not assessed like hypovolemia, sepsis, intravenous contrast administrations, and/or drug interactions. There was no routine protocol for performance of biochemical measurements of serum creatinine concentration beyond day 4 , yet the potential underestimation of AKI incidence in days 5-7 is highly unlikely due to $24.6 \%$ of patients diagnosed with AKI. Finally, vast majority of patients with AKI were diagnosed as stage I and the study was underpowered to detect significant association between SAF and development of severe AKI. However, considering the negative effects of SAF on developing AKI in general and available data on the pathogenetic background of AGEs accumulation in kidney injury, a consistent effect on each stage of AKI may be hypothesized, yet this remains to be elucidated. 


\section{Conclusions}

In conclusion, this is the first study to provide evidence for significant role of AGEs accumulation in development of AKI in patients undergoing major abdominal surgery. Measurement of SAF should be performed in patients undergoing liver resection in order to aid preoperative prediction of AKI, particularly in most susceptible patients undergoing major and prolonged surgical procedures.

\section{Acknowledgements}

Michał Grąt received a stipend for outstanding young scientists from the Ministry of Science and Higher Education of the Republic of Poland (571/ STYP/14/2019)

\section{Institutional Review Board Statement}

The study was conducted according to the guidelines of the Declaration of Helsinki, and approved by the Institutional Ethics Committee of Medical University of Warsaw (KB/2/2018).

\section{Authors' contributions}

Conceptualization: Maciej Krasnodębski, Karolina Grąt, and Michał Grąt. Data curation: Maciej Krasnodębski, Karolina Grąt, Marcin Morawski, Jan Borkowski, Piotr Krawczyk, Andriy Zhylko, Michał Skalski, Piotr Kalinowski, and Michał Grąt. Formal analysis: Maciej Krasnodębski, Karolina Grąt, and Michał Grąt. Funding acquisition: Michał Grąt. Investigation: Maciej Krasnodębski, Karolina Grąt, Marcin Morawski, Jan Borkowski, Piotr Krawczyk, Andriy Zhylko, Michał Skalski, and Michał Grąt. Methodology: Karolina Grąt, Krzysztof Zieniewicz, and Michał Grąt. Project administration: Michał Grąt. Resources: Krzysztof Zieniewicz and Michał Grąt. Supervision: Krzysztof Zieniewicz and Michał Grąt. Writing -original draft: Maciej Krasnodębski and Karolina Grąt. Writing — review and editing: Maciej Krasnodębski, Karolina Grąt, Marcin Morawski, Jan Borkowski, Piotr Krawczyk, Andriy Zhylko, Michał Skalski, Piotr Kalinowski, Krzysztof Zieniewicz, and Michał Grąt. All authors have read and agreed to the published version of the manuscript.

\section{Funding}

The study was funded by National Science Centre, Poland, grant number 2017/26/D/NZ5/00733

\section{Availability of data and materials}

The datasets generated during and/or analyzed during the current study are available from the corresponding author on reasonable request.

\section{Declarations}

\section{Ethics approval and consent to participate}

Informed consent was obtained from all subjects involved in the study.

\section{Competing interests}

The authors declare that they have no competing interests.

\section{Author details}

'Department of General, Transplant and Liver Surgery, Medical University of Warsaw, Warsaw, Poland. ${ }^{2}$ Second Department of Clinical Radiology, Medical University of Warsaw, Warsaw, Poland.

Received: 12 April 2021 Accepted: 3 September 2021

Published online: 15 September 2021

\section{References}

1. Viramontes HD, Taal MW. Skin autofluorescence: an emerging biomarker in persons with kidney disease. Curr Opin Nephrol Hypertens. 2019;28(6):50712. https://doi.org/10.1097/MNH.0000000000000549.

2. Rajaobelina K, Cougnard-Gregoire A, Delcourt C, Gin H, Barberger-Gateau P, Rigalleau $V$. Autofluorescence of skin advanced glycation end products: marker of metabolic memory in elderly population. J Gerontol A Biol Sci Med Sci. 2015 Jul;70(7):841-6. https://doi.org/10.1093/gerona/glu243.
3. Gerrits EG, Smit AJ, Bilo HJ. AGEs, autofluorescence and renal function Nephrol Dial Transplant. 2009;24(3):710-3. https://doi.org/10.1093/ndt/ gfn634.

4. Perrone A, Giovino A, Benny J, Martinelli F. Advanced glycation end products (AGEs): Biochemistry, signaling, analytical methods, and epigenetic effects. Oxid Med Cell Longev. 2020;2020:3818196-18. https://doi.org/10.11 55/2020/3818196

5. Meerwaldt R, Graaff R, Oomen PHN, Links TP, Jager JJ, Alderson NL, et al. Simple non-invasive assessment of advanced glycation endproduct accumulation. Diabetologia. 2004;47(7):1324-30. https://doi.org/10.1007/ s00125-004-1451-2.

6. Gogas Yavuz D, Apaydin T, Imre E, Uygur MM, Yazici D. Skin autofluorescence and carotid intima-media thickness evaluation following bariatric surgery in patients with severe obesity. Obes Surg. 2021;31:105561. https://doi.org/10.1007/s11695-020-05077-z.

7. Saz-Lara A, Álvarez-Bueno C, Martínez-Vizcaíno V, Notario-Pacheco B, SequíDominguez I, Cavero-Redondo I. Are advanced glycation end products in skin associated with vascular dysfunction markers? A meta-analysis. Int J Environ Res Public Health. 2020;17(18):6936. https://doi.org/10.3390/ijerph1 7186936.

8. Jujić A, Östling G, Persson M, Engström G, Nilsson PM, Melander O, et al. Skin autofluorescence as a measure of advanced glycation end product levels is associated with carotid atherosclerotic plaque burden in an elderly population. Diab Vasc Dis Res. 2019;16(5):466-73. https://doi.org/10.1177/14 79164119845319.

9. Ninomiya H, Katakami N, Sato I, Osawa S, Yamamoto Y, Takahara M, et al. Association between subclinical atherosclerosis markers and the level of accumulated advanced glycation end-products in the skin of patients with diabetes. J Atheroscler Thromb. 2018;25(12):1274-84. https://doi.org/10. 5551/jat.44859.

10. Saremi A, Howell S, Schwenke DC, Bahn G, Beisswenger PJ, Reaven PD. VADT Investigators. Advanced glycation end products, oxidation products, and the extent of atherosclerosis during the VA diabetes trial and follow-up study. Diabetes Care. 2017;40(4):591-8. https://doi.org/10.2337/dc16-1875.

11. Sánchez E, Betriu À, Arroyo D, López C, Hernández M, Rius F, et al. Skin Autofluorescence and subclinical atherosclerosis in mild to moderate chronic kidney disease: a case-control study. PLoS One. 2017;12(1):e0170778. https://doi.org/10.1371/journal.pone.0170778.

12. Shardlow A, McIntyre NJ, Kolhe NV, Nellums LB, Fluck RJ, Mclntyre CW, et al. The association of skin autofluorescence with cardiovascular events and allcause mortality in persons with chronic kidney disease stage 3: A prospective cohort study. PLoS Med. 2020;17(7):e1003163. https://doi.org/1 0.1371/journal.pmed.1003163.

13. Fujino Y, Attizzani GF, Tahara S, Wang W, Takagi K, Naganuma T, et al. Association of skin autofluorescence with plaque vulnerability evaluated by optical coherence tomography in patients with cardiovascular disease. Atherosclerosis. 2018;274:47-53. https://doi.org/10.1016/j.atherosclerosis.201 8.03.001.

14. de Vos LC, Lefrandt JD, Dullaart RP, Zeebregts CJ, Smit AJ. Advanced glycation end products: An emerging biomarker for adverse outcome in patients with peripheral artery disease. Atherosclerosis. 2016;254:291-9. https://doi.org/10.1016/j.atherosclerosis.2016.10.012.

15. Sanchis P, Rivera R, Fortuny R, Río C, Mas-Gelabert M. Gonzalez-Freire, et al. Role of advanced glycation end products on aortic calcification in patients with type 2 diabetes mellitus. J Clin Med. 2020;9(6):1751.

16. Wang Y, Luo W, Han J, Khan ZA, Fang Q, Jin Y, et al. MD2 activation by direct AGE interaction drives inflammatory diabetic cardiomyopathy. Nat Commun. 2020 May 1;11(1):2148. https://doi.org/10.1038/s41467-020-1 5978-3.

17. Normand G, Lemoine S, Villien M, Le Bars D, Merida I, Irace Z, et al. AGE content of a protein load is responsible for renal performances: a pilot study. Diabetes Care. 2018:41(6):1292-4. https://doi.org/10.2337/dc1 8-0131.

18. Saulnier PJ, Wheelock KM, Howell S, Weil EJ, Tanamas SK, Knowler WC, et al. Advanced glycation end products predict loss of renal function and correlate with lesions of diabetic kidney disease in american indians with type 2 diabetes. Diabetes. 2016;65(12):3744-53. https://doi.org/10.2337/db1 6-0310.

19. Rabbani N, Thornalley PJ. Advanced glycation end products in the pathogenesis of chronic kidney disease. Kidney Int. 2018;93(4):803-13. https://doi.org/10.1016/j.kint.2017.11.034. 
20. Liebisch M, Wolf G. AGE-induced suppression of EZH2 mediates injury of podocytes by reducing H3K27me3. Am J Nephrol. 2020;51(9):676-92. https://doi.org/10.1159/000510140.

21. Charrin E, Faes C, Sotiaux A, Skinner S Pialoux, V, Joly P, et al. Receptor for advanced glycation end products antagonism blunts kidney damage in transgenic townes sickle mice. Front Physiol. 2019;10:880, DOl: https://doi. org/10.3389/fphys.2019.00880.

22. Garagliano JM, Katsurada A, Miyata K, Derbenev AV, Zsombok A, Navar LG, et al. Advanced glycation end products stimulate angiotensinogen production in renal proximal tubular cells. Am J Med Sci. 2019;357(1):57-66. https://doi.org/10.1016/j.amjms.2018.10.008.

23. Garnier J, Faucher M, Marchese U, Meillat H, Mokart D, Ewald J, et al. Severe acute kidney injury following major liver resection without portal clamping: incidence, risk factors, and impact on short-term outcomes. HPB (Oxford). 2018;20(9):865-71. https://doi.org/10.1016/j.hpb.2018.03.011.

24. Lim C, Audureau E, Salloum C, Levesque E, Lahat E, Merle JC, et al. Acute kidney injury following hepatectomy for hepatocellular carcinoma: incidence, risk factors and prognostic value. HPB (Oxford). 2016;18(6):540-8. https://doi.org/10.1016/j.hpb.2016.04.004.

25. Joliat GR, Labgaa I, Demartines N, Halkic N. Acute kidney injury after liver surgery: does postoperative urine output correlate with postoperative serum creatinine? HPB (Oxford). 2020;22(1):144-50. https://doi.org/10.1016/j. hpb.2019.06.016.

26. Mizota T, Yamamoto Y, Hamada M, Matsukawa S, Shimizu S, Kai S. Intraoperative oliguria predicts acute kidney injury after major abdominal surgery. Br J Anaesth. 2017;119(6):1127-34. https://doi.org/10.1093/bja/aex2 55.

27. Bressan AK, James MT, Dixon E, Bathe OF, Sutherland FR, Ball CG. Acute kidney injury following resection of hepatocellular carcinoma: prognostic value of the acute kidney injury network criteria. Can J Surg. 2018;61(5):E116. https://doi.org/10.1503/CJS.002518.

28. Kambakamba P, Slankamenac K, Tschuor C, Kron P, Wirsching A, Maurer K, et al. Epidural analgesia and perioperative kidney function after major liver resection. Br J Surg. 2015;102(7):805-12. https://doi.org/10.1002/bjs.9810.

29. STARSurg Collaborative. Perioperative intravenous contrast administration and the incidence of acute kidney injury after major gastrointestinal surgery: prospective, multicentre cohort study. Br J Surg. 2020;107(8):1023-1032, DOI: https://doi.org/10.1002/bjs.11453.

30. Kidney Disease: Improving Global Outcomes (KDIGO) Acute Kidney Injury Work Group. KDIGO Clinical Practice Guideline for Acute Kidney Injury. Kidney Inter., Suppl. 2012; 2: 1-138.

31. Levey AS, Eckardt KU, Dorman NM, Christiansen SL, Hoorn EJ, Ingelfinger JR, et al. Nomenclature for kidney function and disease: report of a Kidney Disease: Improving Global Outcomes (KDIGO) Consensus Conference. Kidney Int. 2020;97(6):1117-29. https://doi.org/10.1016/j.kint.2020.02.010.

32. Dindo D, Demartines N, Clavien PA. Classification of surgical complications: a new proposal with evaluation in a cohort of 6336 patients and results of a survey. Ann Surg. 2004;240(2):205-13. https://doi.org/10.1097/01.sla.0000133 083.54934.ae.

33. Lavielle A, Rubin S, Boyer A, Moreau K, Rajaobelina K, Combe C, et al. Skin autofluorescence in acute kidney injury. Crit Care. 2017;21(1):24. https://doi. org/10.1186/s13054-017-1598-0.

34. Myles PS, Mcllroy DR, Bellomo R, Wallace S. Importance of intraoperative oliguria during major abdominal surgery: findings of the Restrictive versus Liberal Fluid Therapy in Major Abdominal Surgery trial. Br J Anaesth. 2019; 122(6):726-33. https://doi.org/10.1016/j.bja.2019.01.010.

35. Dedinská I, Mikolajčík P, Skálová P, Mokáň M, Laca L’. Acute kidney injury after liver resection in elderly patients. BMC Nephrol. 2019 Jul 18;20(1):272. https://doi.org/10.1186/s12882-019-1449-0.

36. STARSurg Collaborative. Prognostic model to predict postoperative acute kidney injury in patients undergoing major gastrointestinal surgery based on a national prospective observational cohort study. BJS Open. 2018;2(6): 400-410. Erratum in: BJS Open. 2019 Aug 02;3(4):549.

37. Slankamenac K, Breitenstein S, Held U, Beck-Schimmer B, Puhan MA, Clavien PA. Development and validation of a prediction score for postoperative acute renal failure following liver resection. Ann Surg. 2009 Nov;250(5):7208. https://doi.org/10.1097/SLA.0b013e3181bdd840.

38. Slankamenac K, Beck-Schimmer B, Breitenstein S, Puhan MA, Clavien PA Novel prediction score including pre- and intraoperative parameters best predicts acute kidney injury after liver surgery. World J Surg. 2013;37(11): 2618-28. https://doi.org/10.1007/s00268-013-2159-6.
39. Lei L, Wang Y, Xue Q, Tong J, Zhou CM, Yang JJ. A comparative study of machine learning algorithms for predicting acute kidney injury after liver cancer resection. PeerJ. 2020;8:e8583. https://doi.org/10.7717/peerj.8583.

40. Cho E, Kim SC, Kim MG, Jo SK, Cho WY, Kim HK. The incidence and risk factors of acute kidney injury after hepatobiliary surgery: a prospective observational study. BMC Nephrol. 2014;15(1):169. https://doi.org/10.1186/14 71-2369-15-169

41. Correa-Gallego C, Berman A, Denis SC, Langdon-Embry L, O'Connor D, Arslan-Carlon $V$, et al. Renal function after low central venous pressureassisted liver resection: assessment of 2116 cases. HPB (Oxford). 2015;17(3): 258-64. https://doi.org/10.1111/hpb.12347.

42. Moon YJ, Jun IG, Kim KH, Kim SO, Song JG, Hwang GS. Comparison of acute kidney injury between open and laparoscopic liver resection: Propensity score analysis. PLoS One. 2017;12(10):e0186336. https://doi.org/10.1371/ journal.pone.0186336.

43. Da Moura SC, Webb M, Waller H, Khunti K, Davies M. Skin autofluorescence, a non-invasive marker of advanced glycation end products: clinical relevance and limitations. Postgrad Med J. 2017;93(1099):289-94.

\section{Publisher's Note}

Springer Nature remains neutral with regard to jurisdictional claims in published maps and institutional affiliations.
Ready to submit your research? Choose BMC and benefit from:

- fast, convenient online submission

- thorough peer review by experienced researchers in your field

- rapid publication on acceptance

- support for research data, including large and complex data types

- gold Open Access which fosters wider collaboration and increased citations

- maximum visibility for your research: over $100 \mathrm{M}$ website views per year

At BMC, research is always in progress.

Learn more biomedcentral.com/submissions 